\title{
Efficacy and safety of systemic hydrocortisone for the prevention of bronchopulmonary dysplasia in preterm infants: a systematic review and meta-analysis
}

\author{
Ian Paul Morris ${ }^{1} \cdot$ Nitin Goel $^{1} \cdot$ Mallinath Chakraborty $^{1,2}$ (D) \\ Received: 4 March 2019 / Revised: 14 April 2019 / Accepted: 6 May 2019 / Published online: 29 May 2019 \\ (C) The Author(s) 2019
}

\begin{abstract}
Early lung inflammation has been implicated in the pathogenesis of bronchopulmonary dysplasia (BPD). We aimed to establish the efficacy and safety of systemic hydrocortisone for the prevention of BPD. A systematic review and meta-analysis were undertaken, with a detailed electronic literature search. Trials involving preterm infants were included if they were randomised to receive systemic hydrocortisone or a placebo. The primary outcome was the composite of survival without BPD at 36-week postmenstrual age (PMA). Results are presented as relative risk (RR) or risk difference (RD) with 95\% confidence intervals (CIs), along with numbers needed to treat (NNT) or harm (NNH). After filtering, 12 studies using early (within 1 week of birth) and two using late hydrocortisone were identified. Early systemic hydrocortisone significantly increased the chances of survival without BPD (RR 1.13, 95\% CI [1.01, 1.26], NNT 18), and survival without moderate-to-severe neurodevelopmental impairment (1.13 $[1.02,1.26]$, NNT 14). Infants who received hydrocortisone had a higher risk of intestinal perforation $(1.69$ [1.07, 2.68], NNH 30 ), primarily with concurrent treatment for patent ductus arteriosus.

Conclusion: Early systemic hydrocortisone is a modestly effective therapy for the prevention of BPD in preterm infants, although some safety concerns remain. No conclusions could be drawn for late hydrocortisone due to the paucity of studies.

What is Known:

- Preterm infants are at high risk of developing bronchopulmonary dysplasia (BPD) and early lung inflammation plays a significant role in its pathogenesis.

- Both early and late systemic dexamethasone seems to reduce the incidence of BPD, but its use is associated with serious neurodevelopmental impairment at follow-up.

What is New:

- Early systemic hydrocortisone significantly improved survival without BPD at 36 weeks and survival without moderate to severe neurodevelopmental impairment on follow up.

- Incidence of gastrointestinal perforation associated with concurrent treatment for PDA was significantly higher, although early systemic hydrocortisone reduced the need for treatment of PDAs.
\end{abstract}

Keywords Preterm $\cdot$ Infant $\cdot$ Bronchopulmonary dysplasia $\cdot$ Hydrocortisone $\cdot$ Steroid $\cdot$ Meta-analysis

Communicated by Patrick Van Reempts

Electronic supplementary material The online version of this article (https://doi.org/10.1007/s00431-019-03398-5) contains supplementary material, which is available to authorized users.

Mallinath Chakraborty

chakrabortym@cardiff.ac.uk

Ian Paul Morris

Ian.Morris3@wales.nhs.uk

Nitin Goel

Nitin.goel@wales.nhs.uk
1 Regional Neonatal Intensive Care Unit, University Hospital of Wales, Cardiff CF14 4XW, UK

2 Centre for Medical Education, Cardiff University, Cardiff, UK 


$\begin{array}{ll}\text { Abbreviations } \\ \text { BPD } & \text { Bronchopulmonary dysplasia } \\ \text { CENTRAL } & \text { Cochrane Central Register of Controlled Trials } \\ \text { CI } & \text { Confidence intervals } \\ \text { CP } & \text { Cerebral palsy } \\ \text { GA } & \text { Gestational age } \\ \text { GI } & \text { Gastrointestinal } \\ \text { IVH } & \text { Intraventricular haemorrhage } \\ \text { MD } & \text { Mean differences } \\ \text { MeSH } & \text { Medical Subject Headings } \\ \text { NDI } & \text { Neurodevelopmental impairment } \\ \text { NEC } & \text { Necrotising enterocolitis } \\ \text { NNH } & \text { Number needed to harm } \\ \text { NNT } & \text { Number needed to treat } \\ \text { PDA } & \text { Patent ductus arteriosus } \\ \text { PMA } & \text { Postmenstrual age } \\ \text { PVL } & \text { Periventricular leucomalacia } \\ \text { RCT } & \text { Randomised controlled trial } \\ \text { ROP } & \text { Retinopathy of prematurity } \\ \text { RR } & \text { Risk ratio } \\ \text { SD } & \text { Standard deviation }\end{array}$

\section{Introduction}

Bronchopulmonary dysplasia (BPD) remains a common complication of preterm birth [1] and is associated with long-term pulmonary morbidity $[2,3]$ and neurodevelopmental impairment (NDI) [4]. Whilst BPD is multi-factorial in aetiology, persistent pulmonary inflammation beginning in utero and continued postnatally by factors including mechanical ventilation, oxidative stress and sepsis has been strongly implicated in the development of the disease [5]. Consequently, corticosteroids as potent anti-inflammatory agents could be of use in reducing the risk of developing BPD.

To date, most studies have considered systemic dexamethasone as the drug of choice in preventing or treating BPD $[6,7]$. Benefits appear to include reduction in the need for mechanical ventilation, the incidence of BPD at 28 days and 36 weeks postmenstrual age (PMA), and neonatal mortality $[6,7]$. However, concerns over longterm neurodevelopmental outcome, particularly when used within the first 7 days of life [6], have led to a more cautious approach in recent years [8] with dexamethasone use usually being reserved for those infants who are ventilator dependant beyond the first few weeks of life.

Systemic hydrocortisone has been postulated as a potentially safer drug to use in terms of long-term neurodevelopment [9, 10]. Several cohort studies have suggested no adverse effect on brain volume or neurodevelopmental outcome in infants receiving systemic hydrocortisone [9, 11], but prospective evidence supporting any benefit in facilitating extubation or reducing rates of BPD have been limited [12]. The Cochrane Neonatal
Group recently updated a meta-analysis of efficacy and safety of systemic steroids in preterm infants, which included data on both hydrocortisone and dexamethasone. We conducted a specific and detailed systematic review and meta-analysis of systemic hydrocortisone to assess the efficacy of early (within the first week of life) or late (beyond the first week of life) postnatal use for the prevention of BPD in preterm infants compared to placebo or active control, along with its short- and long-term safety. Our analysis includes data from two extra studies, one using early hydrocortisone and a recent large study using late hydrocortisone. We have compared more clinically relevant outcomes (treated for hypertension, hyperglycaemia, patent ductus arteriosus [PDA] or retinopathy of prematurity [ROP], rather than incidence) to help clinicians in taking decisions on the ward. In addition, we have conducted a sub-group analysis of studies which had short-term respiratory endpoints as their primary outcome (BPD studies), excluding studies where hydrocortisone was used to treat hypotension, for more robust results.

\section{Methods}

\section{Objectives}

A systematic review and meta-analysis, using methods from the Cochrane Collaboration, to assess the efficacy and safety of systemic hydrocortisone for the prevention of BPD in preterm infants ( $<37$ weeks gestational age [GA] at birth), when compared with placebo (or other non-steroidal active control with no known effect on BPD) in published studies.

\section{Inclusion criteria}

Prospective RCTs involving preterm infants were eligible for inclusion in the review. Trials were included if participating infants were randomised to receive systemic hydrocortisone (with or without a second active drug which has no known effects on BPD) started within the first week after birth (early) or after the first week (late), or a placebo (or any other nonsteroidal active control with no known effects on BPD), and reported outcomes relevant to the review (please see below). Studies were grouped according to whether hydrocortisone was started early, or late, and separate analyses were conducted for each group.

\section{Search strategy}

We developed a search strategy using keywords and MESH terms, as detailed in the supplementary information, from two main databases: Embase and Medline. A separate search using keyword was conducted on the Cochrane Central Register of Controlled Trials (CENTRAL). The databases were searched 
in March 2018, at the end of the third week. This search was rerun in February 2019, and one further relevant paper on late hydrocortisone was identified. References in included studies were also screened manually for inclusion. The search included papers in all languages from all countries.

\section{Outcomes}

The primary outcome was survival without BPD at 36 weeks PMA (composite outcome). Data on several secondary outcomes were collected, including those on efficacy (survival to 36 weeks PMA and to discharge, and BPD at 36 weeks in survivors), short-term safety (sepsis, pulmonary air-leak or haemorrhage, gastrointestinal [GI] bleeding or perforation, hyperglycaemia and its treatment, hypertension and its treatment, intraventricular haemorrhage [IVH], periventricular leucomalacia $[\mathrm{PVL}]$ and necrotising enterocolitis [NEC]), other relevant short-term outcomes (home oxygen in survivors, duration of mechanical ventilation and total stay, patent ductus arteriosus [PDA] and its treatment, and retinopathy of prematurity $[\mathrm{ROP}]$ and its treatment) and long-term safety outcomes up to 2 years of age (death until last follow-up, survival without any NDI, survival without moderate-to-severe NDI, any and severe NDI at follow up and cerebral palsy [CP]).

\section{Definitions}

BPD was defined as respiratory support and/or supplemental oxygen requirement at 36 weeks corrected GA and classified as moderate or severe BPD by Jobe and Bancalari. [13] Grades of IVH were as classified by Lu-Ann Papile [14]. Modified classification of NEC was by Walsh et al. [15]. PVL, PDA, ROP and NDI were defined as reported by authors in the studies.

\section{Data collection}

Data was collected on characteristics of studies and planned outcomes using a standardised data collection form (supplementary Table 1) by at least two authors independently and then cross-checked for accuracy. Attempts were made to clarify methods and request additional data from corresponding authors if data on some relevant outcomes were not reported. These are mentioned in the relevant tables in the "Results" section.

\section{Statistical analysis}

1. Measurement of Treatment Effect

Statistical analysis was conducted using Review Manager (RevMan) version 5.3 (Copenhagen: The Nordic Cochrane Centre, The Cochrane Collaboration, 2014). Only summary estimates are reported (no individual patient meta-analysis). For continuous outcomes, the mean and standard deviation (SD) (such as duration of respiratory support) reported in each study were collected and analysed and presented as mean differences (MD) along with 95\% confidence intervals (CIs). Means and SDs were estimated from studies (total six studies) reporting continuous outcomes as medians and interquartile ranges by using methods described by Wan et al. [16]. For categorical outcomes (such as survival or BPD), data was extracted for each intervention group for analysis and presented as risk ratio (RRs) with 95\% CI. Estimation of number needed to treat/harm, along with their $95 \%$ confidence intervals, were undertaken for significant results using GraphPad Prism QuickCalc (GraphPad software 2017, https://graphpad. com/quickcalcs/), according to the methods of Newcombe/ Wilson with continuity correction [17]. All main results were rated independently by the authors using the Grade system (https://gdt.gradepro.org/app/handbook/handbook.html) and presented in a summary-of-findings (SoF) table. A prespecified sub-group analysis was conducted by including studies in which hydrocortisone was used for the prevention of BPD (and not for the treatment of systemic hypotension). Significance was set at $p<0.05$.

\section{Assessment of Bias in Included Studies}

All studies included in final analysis were assessed for risk of bias (low, high, or unknown) using a domain-based flowsheet (as used by the Cochrane Collaboration). For each domain, a judgement was made on likely magnitude and direction of the bias and its likely impact on the outcomes. Disagreements were resolved by consensus. A judgement was made on the overall risk of bias based on the above domains.

\section{Assessment of Heterogeneity}

Heterogeneity was quantified using Inaccuracy ${ }^{2}\left(\mathrm{I}^{2}\right)$ statistic and stratified as moderate $\left(\mathrm{I}^{2}<50 \%\right)$ or substantial $\left(\mathrm{I}^{2} \geq\right.$ $50 \%$ ) (http://handbook.cochrane.org/). To calculate pooled estimate of effect size, a fixed-effect model was used if moderate heterogeneity was detected, and a random-effect model was used if substantial heterogeneity was detected.

\section{Ethical approval}

No specific ethical approval was required for this metaanalysis as all original studies had individual ethical approval. The review was prospectively registered on PROSPERO with an identification number of CRD42017073615 (http://www. crd.york.ac.uk/PROSPERO/display_record.asp?ID= CRD42017073615). 


\section{Results}

Search records, filtering and study flow diagram is presented in Fig. 1. In total, 22 full-text articles and conference abstracts were included in the qualitative analysis - 18 for the early use and 4 for the late use of hydrocortisone.

One full-text article and one conference paper for the early use and one full-text paper for the late use of hydrocortisone were excluded from final meta-analysis (details below), leaving 16 papers for the early use and 3 for the late use in the quantitative synthesis.

A summary of the risk of bias in the included studies as agreed by the authors is presented in supplementary Fig. 1 . Although some of the domains in the included studies had unclear or high risk of bias, all the studies had an overall low risk of bias.
A total of 13 studies investigated the use of early hydrocortisone in preterm infants in the first week of life of which 12 were published as full-text articles [18-29]. One study was only published as an abstract [30] and used both hydrocortisone and caffeine in the experimental group, with placebo in the control group. As caffeine is known to have a significant effect on BPD, it was not possible to separate the effects of these two drugs from each other in the results from this study, and this abstract was excluded from further analysis. Of the 12 other studies which were included in the quantitative analysis, four published follow-up studies which were included in the long-term analysis [31-35]. One of the follow-up studies reported outcomes at pre-school age and was not included in the meta-analysis as this was the only study to do so [34]. Details of all included studies are presented in Table 1 and supplementary Table 2 . Both the pooled mean GA (MD 0.05 weeks,
Fig. 1 Study flow diagram, showing filtering of papers at each stage

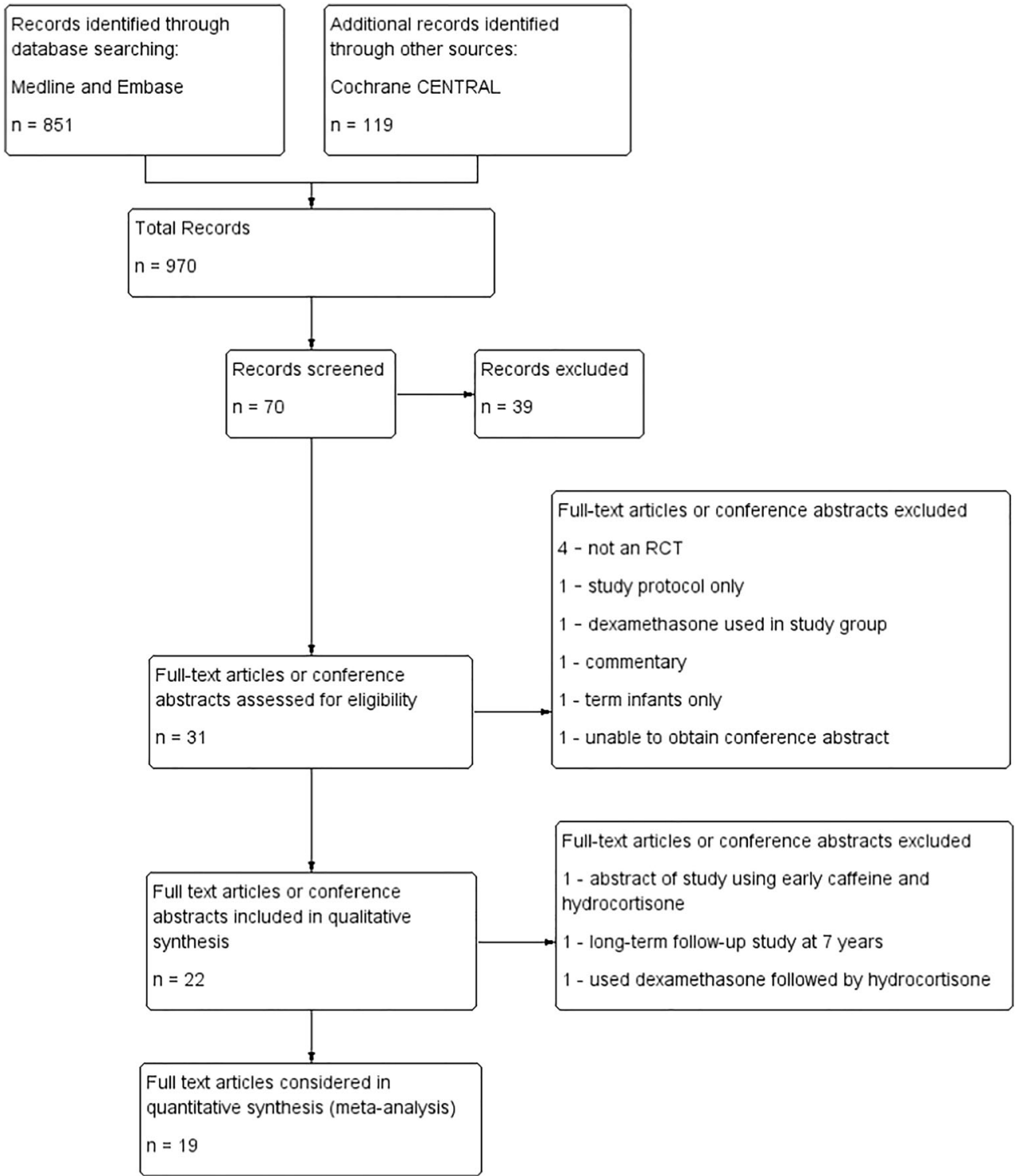




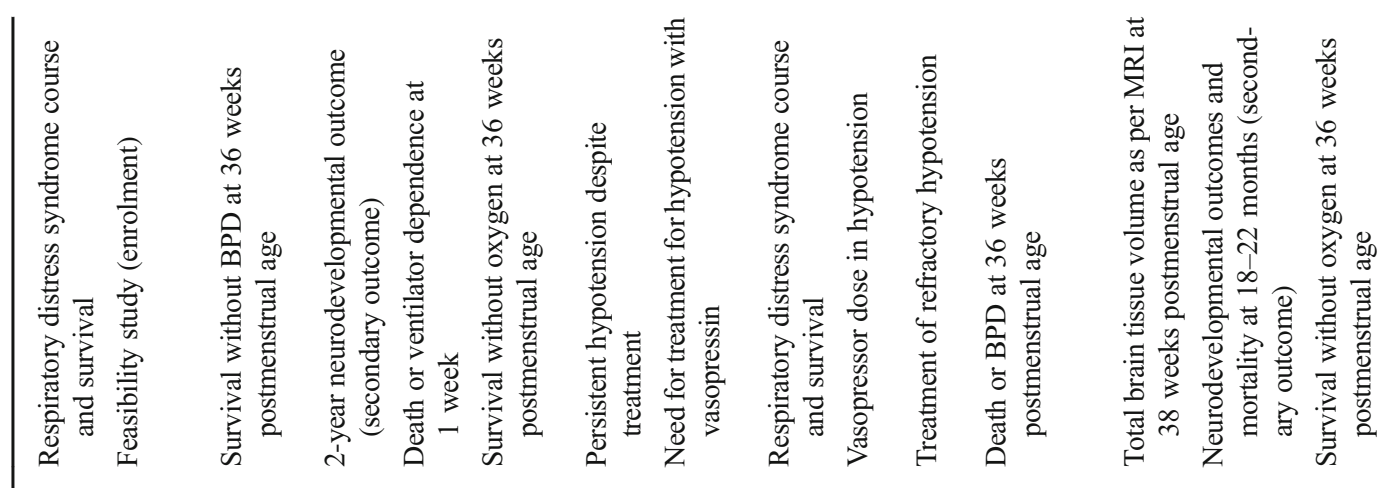

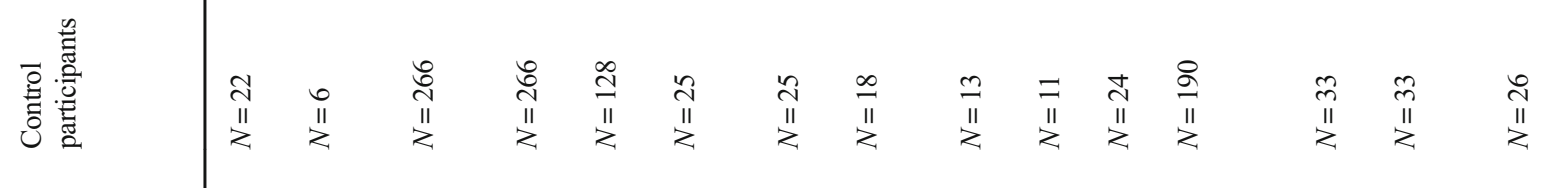

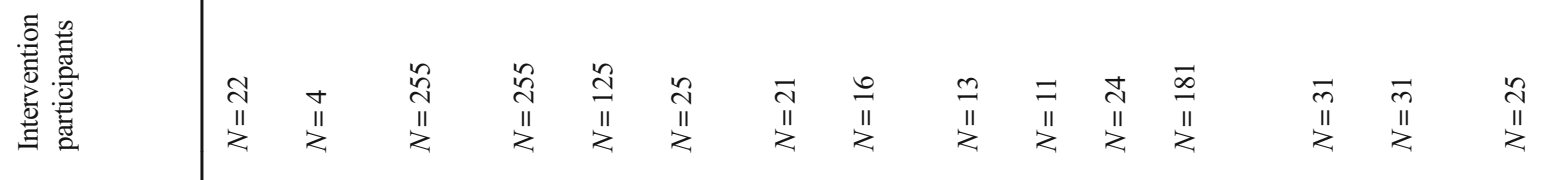

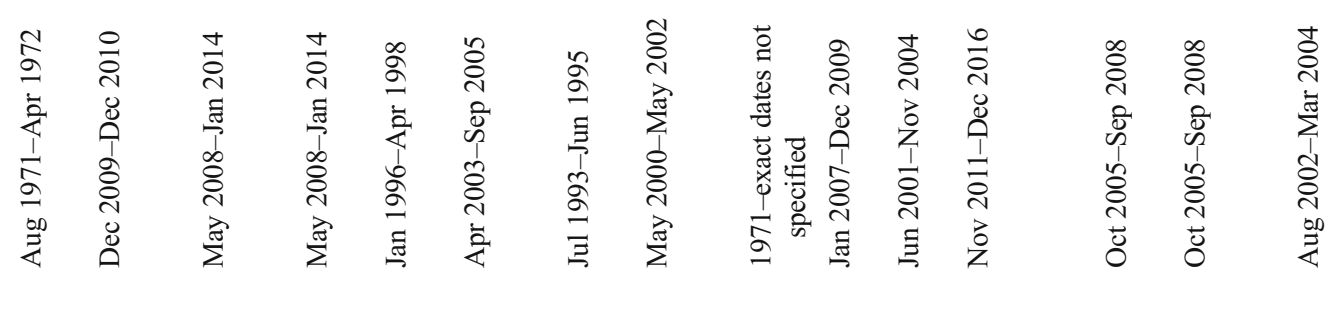

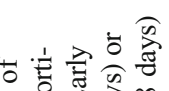

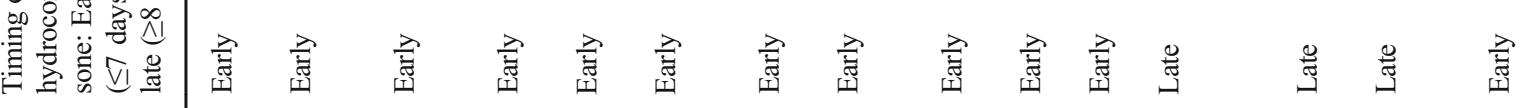

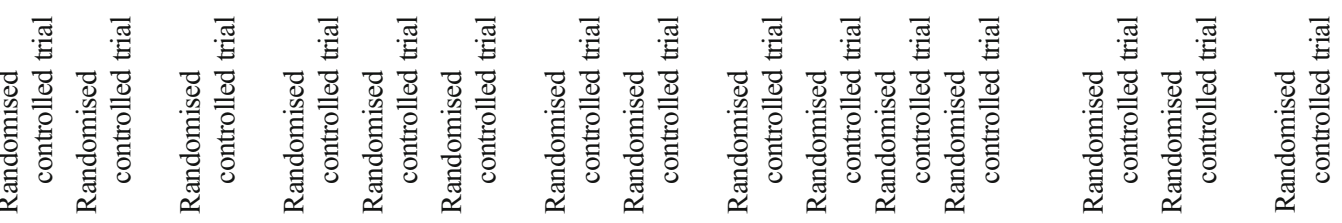

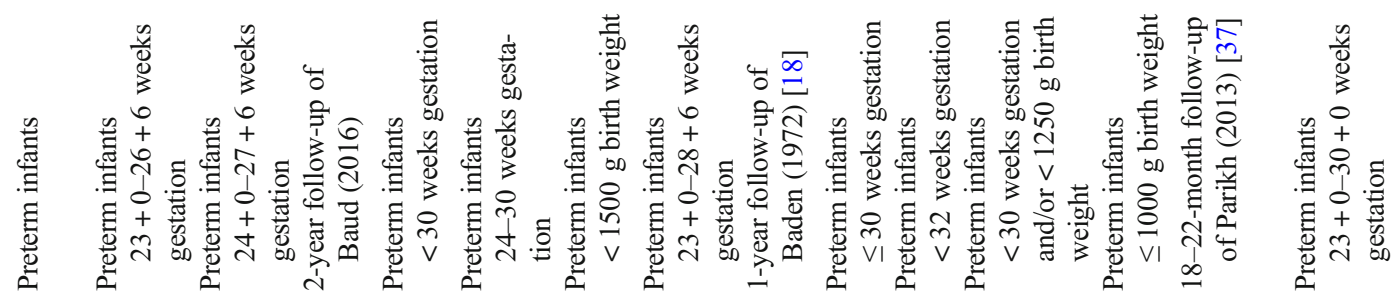

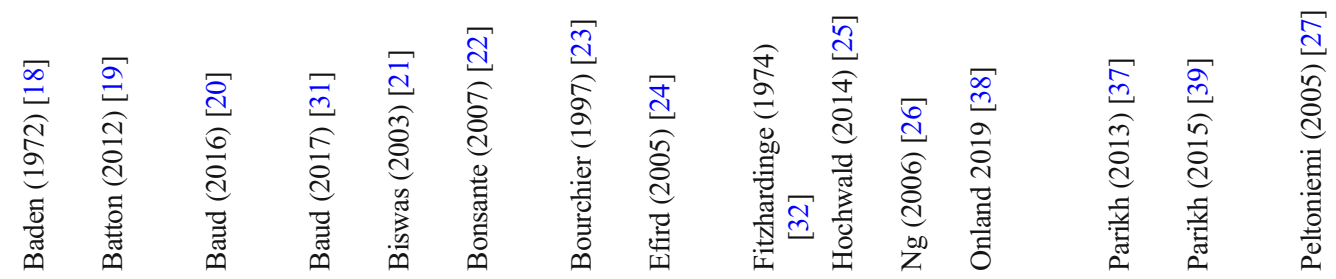


95\% CI $[-0.09,0.18], p=0.49)$ and mean birth weight $(-$ $3.92 \mathrm{~g},[-21.08,13.24], p=0.65)$ of the full cohort were comparable between the two groups of infants from the included studies.

Summary of findings after early use of hydrocortisone is presented in Table 2. A total of 10 studies reported the primary outcome. Pooled estimate including data from all of the studies (1378 infants) showed a significantly higher risk of survival without BPD for the group of infants receiving hydrocortisone in the first week of life (RR 1.13 [1.01, 1.26], $p=0.04$, Fig. 2a), compared to placebo (or other active control). From our estimate, 18 preterm infants would need to be treated (NNT) with early hydrocortisone for one infant to survive without BPD (95\% CI 9.2, 314.2). A funnel plot for this outcome did not suggest a significant publication bias (supplementary Fig. 2a). As evident from Table 1, not all studies intended to look at the outcome of BPD; some studies used hydrocortisone to treat systemic hypotension in the first week of life [19, 21, 23-25]. We undertook a sub-group analysis of five studies (1019 infants) using early systemic hydrocortisone for the prevention of BPD as their primary outcome [20, 22, 27-29], and pooled data also showed a significantly higher risk of survival without BPD for infants in the hydrocortisone group (1.19 [1.04, 1.35], $p<0.01$, Fig. $2 b)$. Thirteen infants would have to be treated with early systemic hydrocortisone for one infant to survive without BPD (95\% CI 7.1, 56.1).

When all studies were included, the incidence of BPD in survivors at 36 weeks $(0.91[0.81,1.03], p=0.15$, Fig. 3a) and total survival to 36 weeks (1.03 [0.98, $1.08], p=0.19$ ) were not significantly different between the groups. However, in the sub-group analysis of the BPD studies, the risk of BPD in survivors at 36 weeks was significantly lower $(0.84$ [0.72, 0.98], $p=0.03$, NNT 14 [7.2, 164.6], Fig. 3b), although survival to 36 weeks was comparable between the groups $(1.04[0.98,1.10]$ $p=0.20)$. Total survival to discharge was higher in the hydrocortisone group (1.05 [1.00, 1.11], $p=0.04$, NNT $24[12.1,524.2])$ when all studies were included but failed to reach statistical significance in the sub-group analysis $(1.06$ [1.00, 1.13], $p=0.06)$. Gastrointestinal perforation, which was significantly higher in the group of infants receiving hydrocortisone (all studies: 1.69 [1.07, 2.68], $p=0.03$, number needed to harm $(\mathrm{NNH}) 30$ [15.9, 193.9], Fig. 4a; BPD-studies: 1.76 [1.09, 2.84], $p=0.02$, NNH 28 [15.0, 159.2], Fig. 4b),

All short-term safety and other outcomes during the first admission of the infants from birth to discharge (or death) are summarised in Table 3 along with the sub-group analysis. Early treatment with hydrocortisone significantly reduced the risk of treatment for PDA (all-studies: 0.66 [0.52, 0.84], $p<0.01$, NNT $11[6.8,25.9]$, supplementary Fig. 3a; BPD- 


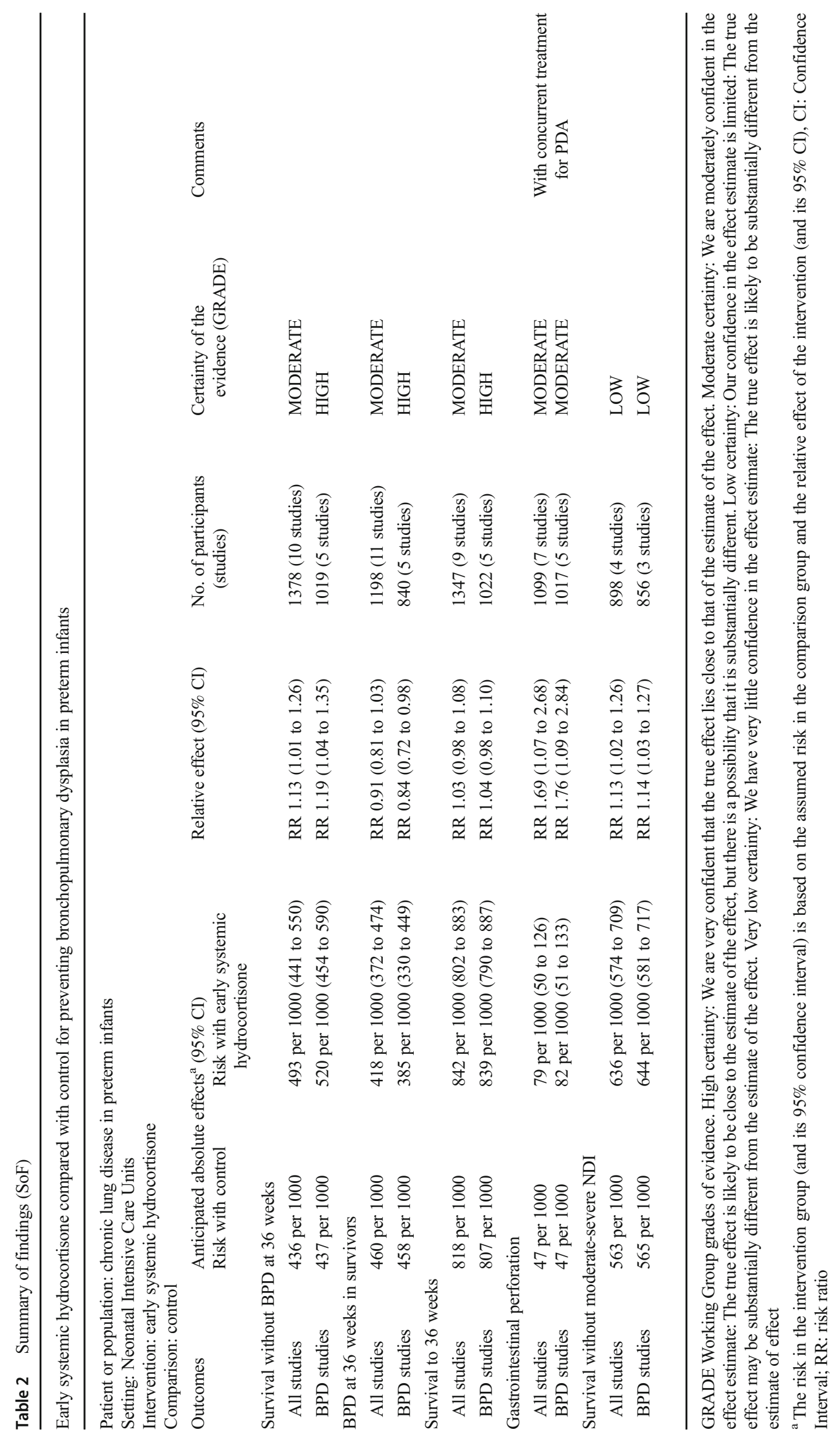


a

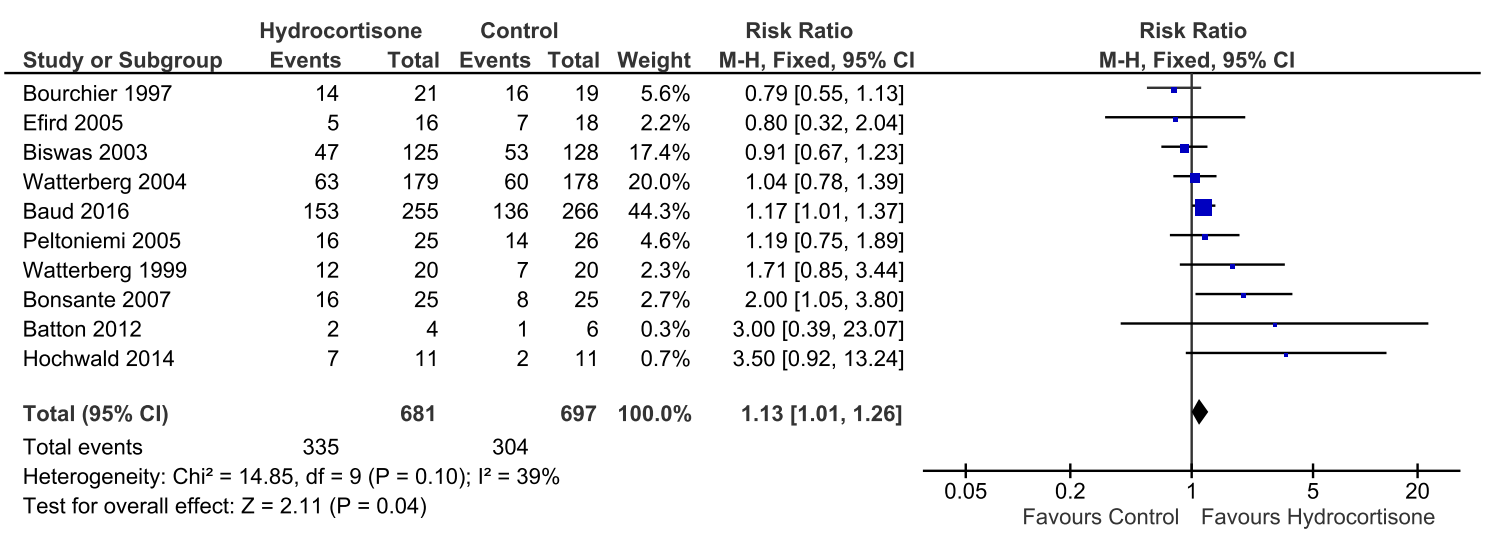

b

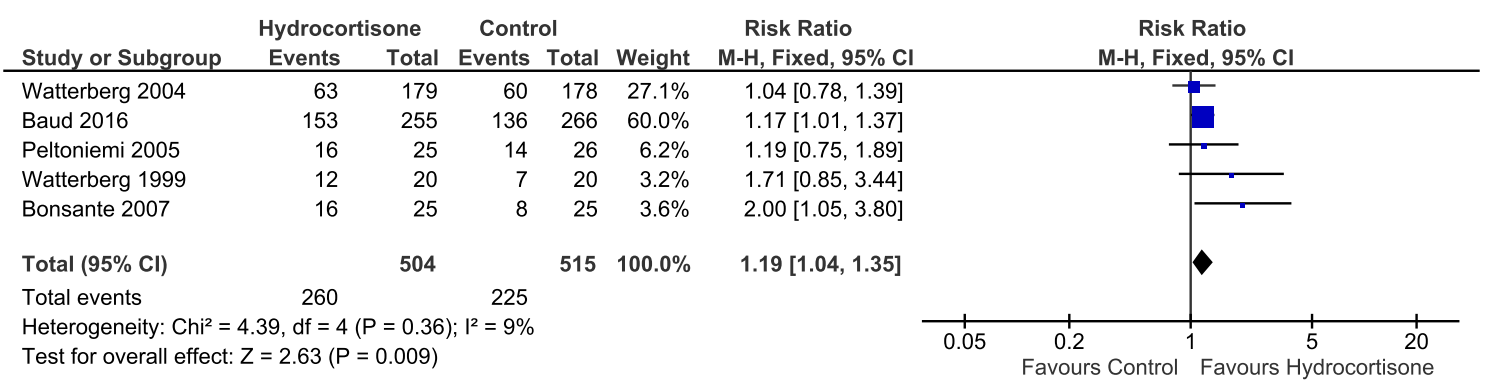

Fig. 2 Forest-plot of pooled effect estimate for survival without BPD at 36 weeks corrected gestational age with early systemic hydrocortisone for a all studies and $\mathbf{b}$ studies with BPD as primary outcome

studies: $0.66[0.49,0.88], p<0.01$, NNT $11[6.3,37.6]$, supplementary Fig. 3b).

Only a minority of the original studies reported any long-term outcomes (5 out of 11). The main results are summarised in Table 4. Infants who received early hydrocortisone had a significantly higher risk of survival without moderate-severe NDI (all studies: 1.13 [1.02, 1.26], $p=0.02$, supplementary Fig. 4a; BPD-studies: 1.14 [1.03, 1.27], $p=0.02$, supplementary Fig. $4 b$ ), compared to infants in the control group. For every 14 infants treated with early hydrocortisone after birth, one infant is estimated to survive without moderate-severe NDI (NNT, 95\% CI $7.4,129.4)$. If only the BPD studies were considered, the NNT was 13 (95\% CI 7.0, 81.1).

Three studies randomised infants to receive hydrocortisone after the first week of life [36-38], with one follow-up study [39]. The study by Kazzi et al. treated preterm infants with systemic dexamethasone in the first week of life (7 days), followed by systemic hydrocortisone in tapering doses for the next 10 days. As early dexamethasone is known to have a significant effect on BPD [6], it was not possible to separate its effect from those of hydrocortisone. Thus, this trial was excluded from further analysis. Summary of results from the remaining two trials are presented in Table 5. Although both of these studies used hydrocortisone in ventilator-dependent preterm infants beyond the first week of life for the prevention of BPD, there were several differences between their design and conduct. Parikh and colleagues [37] randomised infants with a birth weight $\leq 1000 \mathrm{~g}$ between 10 and 21 days of life to a cumulative dose of $17 \mathrm{mg} / \mathrm{kg}$ of hydrocortisone over 7 days or placebo, while Onland and colleagues [38] randomised infants born at $<30$ weeks (or $<1250 \mathrm{~g}$ birth weight) between 7 and 14 days of life to a cumulative dose of $72.5 \mathrm{mg} / \mathrm{kg}$ of hydrocortisone over 22 days or placebo. Results reported by the two trials were not always comparable, and only some of the outcomes could be pooled together in the meta-analysis presented in Table 5. Apart from a significantly higher risk of needing treatment for hyperglycaemia in infants receiving hydrocortisone (2.31 [1.30, 4.11], $p<0.01)$, all other outcomes were comparable between the groups. There was a trend towards more infants in the hydrocortisone group surviving to discharge $(1.12[0.99,1.26], p=0.07)$. Due to the paucity of studies, no recommendations can be made for the use of late hydrocortisone for the prevention of BPD in preterm infants.

\section{Discussion}

Preterm infants receiving early systemic hydrocortisone had a significantly higher chance of survival without BPD (composite outcome) at 36 weeks PMA, compared to control infants $(\mathrm{NNT}=18)$. This effect was also evident 
a

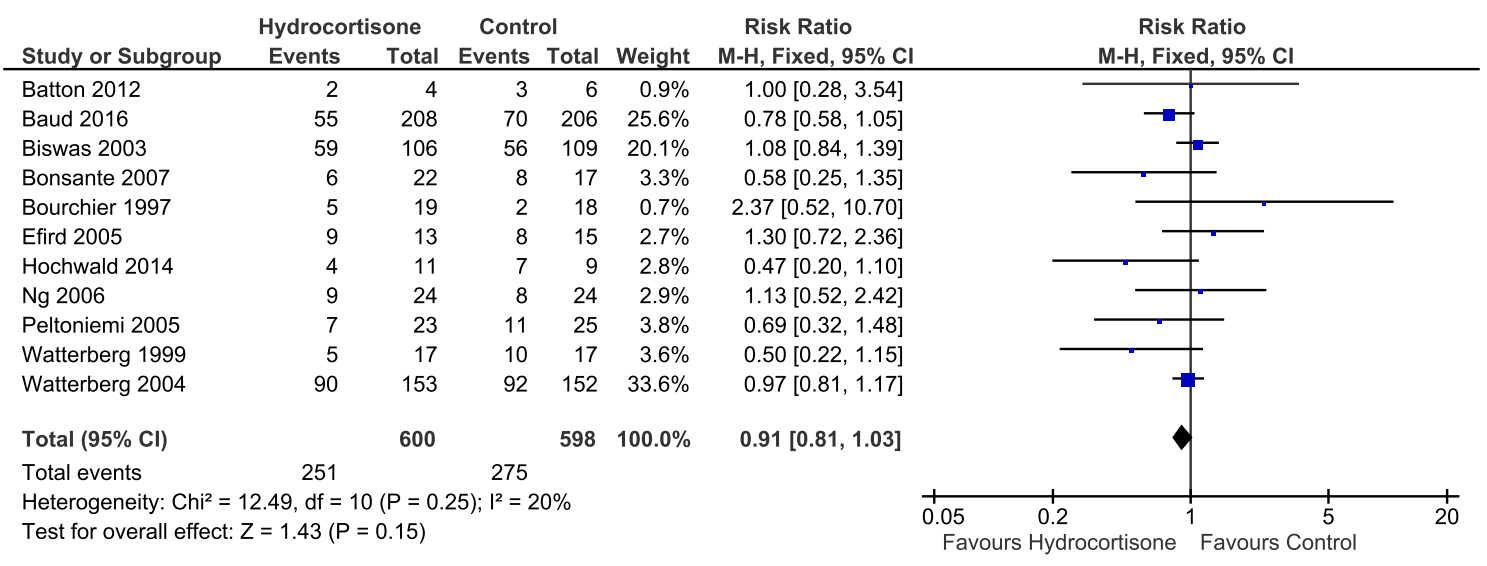

b

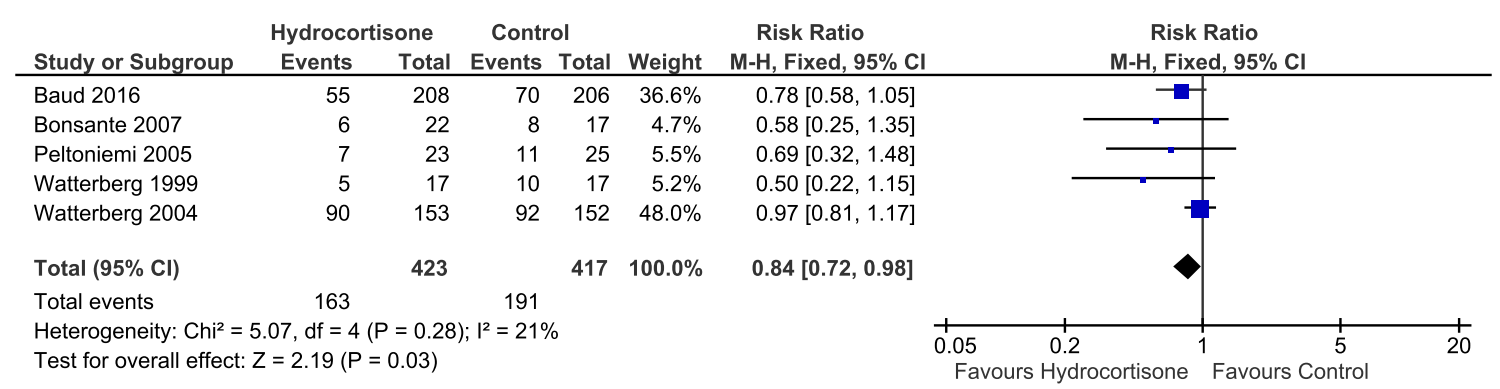

Fig. 3 Forest plots of effect pooled estimates for BPD at 36 weeks corrected gestational age in survivors with early systemic hydrocortisone for a all studies and $\mathbf{b}$ studies with BPD as primary outcome

a

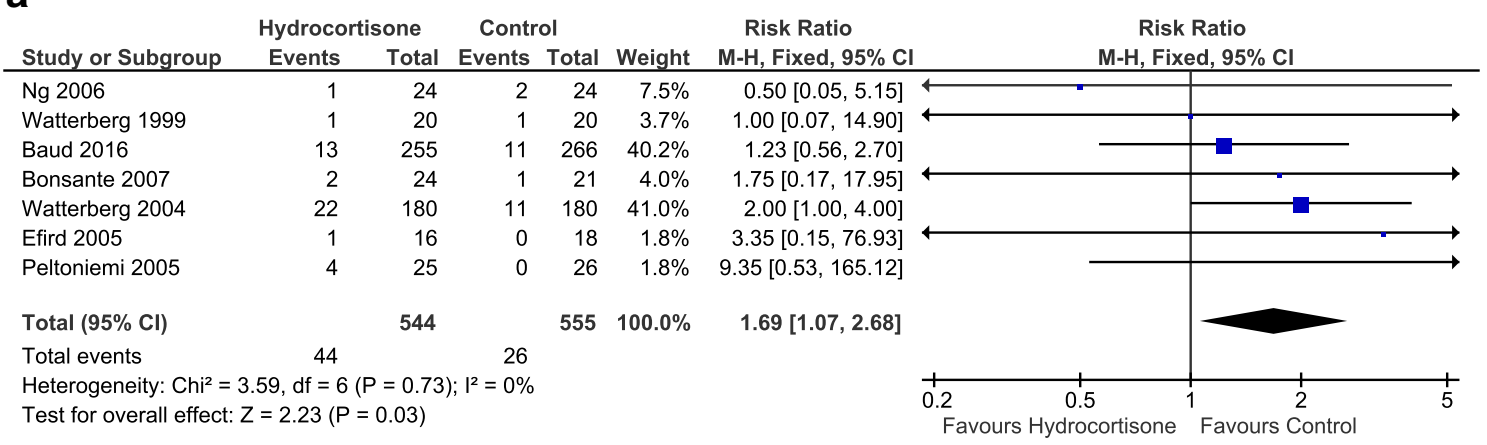

b

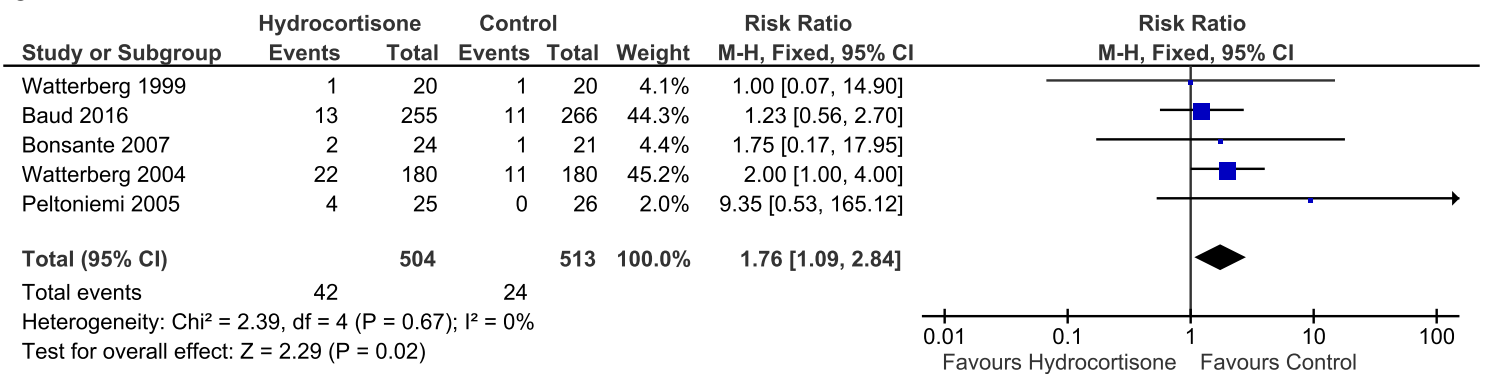

Fig. 4 Forest plots of pooled effect estimates for gastrointestinal perforation with early systemic hydrocortisone for $\mathbf{a}$ all studies and $\mathbf{b}$ studies with BPD as primary outcome 
Table 3 Summary of short-term safety and other outcomes during stay for use of early hydrocortisone

\begin{tabular}{|c|c|c|c|c|c|c|c|c|}
\hline \multirow[t]{2}{*}{ Outcome } & \multicolumn{2}{|c|}{ Hydrocortisone } & \multicolumn{2}{|l|}{ Control } & \multirow[t]{2}{*}{ Number of trials } & \multirow{2}{*}{$\begin{array}{l}\text { Risk ratio }(95 \% \text { CI) } \\
\text { OR SMD }(95 \% \text { CI) }\end{array}$} & \multirow[t]{2}{*}{$p$ value } & \multirow[t]{2}{*}{$\mathrm{NNT} / \mathrm{H}(95 \% \mathrm{CI})$} \\
\hline & Events & Total & Events & Total & & & & \\
\hline \multicolumn{9}{|l|}{ All studies } \\
\hline Survival to discharge & 602 & 728 & 583 & 743 & 12 & $1.05(1.00,1.11)$ & 0.04 & $24(12.1,524.2)$ \\
\hline Sepsis $^{\mathrm{a}}$ & 253 & 702 & 236 & 714 & 10 & $1.09(0.95,1.25)$ & 0.22 & \\
\hline Pulmonary air leak & 48 & 609 & 43 & 623 & 5 & $1.13(0.77,1.67)$ & 0.54 & \\
\hline Pulmonary haemorrhage & 53 & 584 & 41 & 598 & 4 & $1.32(0.89,1.95)$ & 0.16 & \\
\hline GI bleeding & 2 & 25 & 1 & 26 & 1 & $2.08(0.20,21.52)$ & 0.54 & \\
\hline Treated for hyperglycaemia & 207 & 508 & 192 & 520 & 6 & $1.10(0.95,1.28)$ & 0.20 & \\
\hline Treated for hypertension & 4 & 196 & 5 & 198 & 2 & $0.80(0.22,2.93)$ & 0.74 & \\
\hline Any IVH & 93 & 217 & 82 & 222 & 3 & $1.16(0.92,1.46)$ & 0.20 & \\
\hline IVH grade III-IV & 102 & 687 & 108 & 704 & 10 & $0.97(0.76,1.25)$ & 0.83 & \\
\hline PVL & 21 & 584 & 30 & 607 & 8 & $0.75(0.44,1.27)$ & 0.28 & \\
\hline NEC & 54 & 705 & 55 & 719 & 11 & $1.00(0.70,1.43)$ & 0.99 & \\
\hline Discharged with home oxygen (survivors) & 33 & 348 & 43 & 341 & 4 & $0.76(0.50,1.15)$ & 0.20 & \\
\hline Duration of mechanical ventilation (days) & & 425 & & 430 & 8 & $-0.63(-3.02,1.77)$ & 0.61 & \\
\hline Duration of stay (days) ${ }^{\mathrm{c}}$ & & 385 & & 388 & 7 & $-1.94(-6.76,2.89)$ & 0.43 & \\
\hline Treated for PDA ${ }^{\mathrm{d}}$ & 79 & 439 & 125 & 458 & 5 & $0.66(0.52,0.84)$ & $<0.01$ & $11(6.8,25.9)$ \\
\hline Treated for ROP & 25 & 477 & 30 & 486 & 5 & $0.83(0.50,1.37)$ & 0.46 & \\
\hline \multicolumn{9}{|l|}{ BPD studies } \\
\hline Survival to discharge & 417 & 505 & 401 & 515 & 5 & $1.06(1.00,1.13)$ & 0.06 & \\
\hline Sepsis & 179 & 505 & 155 & 514 & 5 & $1.17(0.99,1.40)$ & 0.07 & \\
\hline Pulmonary air leak & 30 & 460 & 29 & 471 & 3 & $1.04(0.64,1.70)$ & 0.86 & \\
\hline Pulmonary haemorrhage & 37 & 435 & 30 & 446 & 2 & $1.26(0.79,2.01)$ & 0.33 & \\
\hline GI bleeding & 2 & 25 & 1 & 26 & 1 & $2.08(0.20,21.52)$ & 0.54 & \\
\hline Treated for hyperglycaemia & 196 & 460 & 184 & 472 & 3 & $1.09(0.94,1.28)$ & 0.25 & \\
\hline Treated for hypertension & 4 & 180 & 5 & 180 & 1 & $0.80(0.22,2.93)$ & 0.74 & \\
\hline Any IVH & 93 & 217 & 82 & 222 & 3 & $1.16(0.92,1.46)$ & 0.20 & \\
\hline IVH grade III-IV & 77 & 497 & 74 & 509 & 5 & $1.07(0.80,1.44)$ & 0.65 & \\
\hline PVL & 16 & 415 & 23 & 431 & 4 & $0.72(0.39,1.34)$ & 0.30 & \\
\hline NEC & 29 & 504 & 31 & 513 & 5 & $0.95(0.58,1.55)$ & $0 . .84$ & \\
\hline Discharged with home oxygen (survivors) & 18 & 246 & 24 & 238 & 3 & $0.74(0.42,1.28)$ & 0.28 & \\
\hline Duration of mechanical ventilation (days) & & 249 & & 249 & 4 & $-2.69(-6.98,1.59)$ & 0.22 & \\
\hline Duration of stay (days) & & 222 & & 221 & 4 & $-1.02(-6.35,4.31)$ & 0.71 & \\
\hline Treated for $\mathrm{PDA}^{\mathrm{d}}$ & 54 & 300 & 85 & 312 & 3 & $0.66(0.49,0.88)$ & $<0.01$ & $11(6,3,37.6)$ \\
\hline Treated for ROP & 24 & 453 & 28 & 462 & 4 & $0.85(0.51,1.42)$ & 0.54 & \\
\hline
\end{tabular}

${ }^{\text {a }}$ Only first episode of sepsis included from Biswas 2003

${ }^{\mathrm{b}}$ Bourchier (1997) and Efird (2005) reported IVH grades II-IV

${ }^{\mathrm{c}}$ Efird (2005) reported duration of stay in survivors only

${ }^{\mathrm{d}}$ Baud (2016) and Biswas (2003) reported numbers of infants who had surgery for PDA

in a sub-group of trials where BPD was the intended primary outcome with NNT of 13. Risk of gastrointestinal perforation was significantly higher in infants receiving hydrocortisone. At follow-up (up to 2 years of age), infants receiving early systemic hydrocortisone had a significantly higher chance of survival without moderate-to- severe NDI (composite outcome) compared to control infants (NNT 14).

Our review on hydrocortisone has been updated since the Cochrane review published in 2017, with several differences. We identified two extra eligible studies, which have been included in the meta-analysis. We have conducted a sub-group 
Table 4 Summary of long-term safety outcomes of early hydrocortisone

\begin{tabular}{|c|c|c|c|c|c|c|c|c|}
\hline \multirow[t]{2}{*}{ Outcome } & \multicolumn{2}{|c|}{ Hydrocortisone } & \multicolumn{2}{|l|}{ Control } & \multirow[t]{2}{*}{ Number of trials } & \multirow[t]{2}{*}{ Risk ratio $(95 \% \mathrm{CI})$} & \multirow[t]{2}{*}{$p$ value } & \multirow{2}{*}{$\begin{array}{l}\text { NNT } \\
(95 \% \text { CI) }\end{array}$} \\
\hline & Events & Total & Events & Total & & & & \\
\hline \multicolumn{9}{|l|}{ All studies } \\
\hline Death until last FU & 91 & 482 & 112 & 494 & 4 & $0.83(0.65,1.06)$ & 0.14 & \multirow{5}{*}{$14(7.4,129.4)$} \\
\hline Survival without moderate-severe NDI & 281 & 443 & 256 & 455 & 4 & $1.13(1.02,1.26)$ & 0.02 & \\
\hline Any NDI at FU & 41 & 138 & 45 & 138 & 2 & $0.91(0.64,1.29)$ & 0.60 & \\
\hline Severe NDI at FU & 19 & 217 & 26 & 207 & 2 & $0.70(0.40,1.22)$ & 0.20 & \\
\hline Cerebral palsy (survivors and FU) & 34 & 374 & 31 & 359 & 5 & $1.06(0.67,1.67)$ & 0.81 & \\
\hline \multicolumn{9}{|l|}{ BPD studies } \\
\hline Death until last FU & 83 & 460 & 103 & 472 & 3 & $0.83(0.64,1.07)$ & 0.15 & \multirow{5}{*}{$13(7.0,81.1)$} \\
\hline Survival without moderate-severe NDI & 271 & 422 & 245 & 434 & 3 & $1.14(1.03,1.27)$ & 0.02 & \\
\hline Any NDI at FU & 39 & 126 & 44 & 126 & 1 & $0.89(0.62,1.26)$ & 0.50 & \\
\hline Severe NDI at FU & 19 & 217 & 26 & 207 & 2 & $0.70(0.40,1.22)$ & 0.20 & \\
\hline Cerebral palsy (survivors and FU) & 32 & 362 & 30 & 347 & 4 & $1.03(0.64,1.64)$ & 0.91 & \\
\hline
\end{tabular}

Results from Bonsante 2007 were reported in the paper by Peltoniemi 2009, Fitzhardinge reported severe NDI at 1-year of age, and Watterberg 2007 reported severe NDI)

$F U$ follow-up

analysis with all studies where BPD was the primary outcome. In addition, we have looked at more clinically relevant outcomes which would help clinicians to take decisions on the ward, including proportions of infants in each group who actually received treatment for hyperglycaemia, hypertension, PDA and ROP. The diagnosis and the exact clinical significance of these morbidities are controversial; treatment for these morbidities indicate crossing of a pragmatic threshold, which is of real clinical interest (rather than just the diagnosis). Thus, we believe these clinically useful outcomes are more relevant for clinicians. We have used only published data for our analysis, which can be easily accessed and verified by all readers.

Our review includes all published trials of postnatal hydrocortisone (14 trials in total), including 1633 preterm infants.

Table 5 Summary of outcomes of late hydrocortisone. ( $F U$ follow-up)

\begin{tabular}{|c|c|c|c|c|c|c|c|}
\hline \multirow[t]{2}{*}{ Outcome } & \multicolumn{2}{|c|}{ Hydrocortisone } & \multicolumn{2}{|l|}{ Control } & \multirow[t]{2}{*}{ Number of trials } & \multirow{2}{*}{$\begin{array}{l}\text { Risk ratio }(95 \% \mathrm{CI}) \\
\text { SMD }(95 \% \mathrm{CI})\end{array}$} & \multirow[t]{2}{*}{$p$ value } \\
\hline & Events & Total & Events & Total & & & \\
\hline Survival without BPD at 36 weeks postmenstrual age & 81 & 212 & 77 & 222 & 2 & $1.10(0.88,1.37)$ & 0.41 \\
\hline BPD at 36 weeks in survivors & 120 & 176 & 115 & 170 & 2 & $1.01(0.88,1.17)$ & 0.87 \\
\hline Survival to 36 weeks postmenstrual age & 176 & 212 & 170 & 223 & 2 & $1.09(0.99,1.20)$ & 0.08 \\
\hline Survival to discharge & 153 & 212 & 144 & 223 & 2 & $1.12(0.99,1.26)$ & 0.07 \\
\hline Sepsis & 104 & 212 & 126 & 223 & 2 & $0.87(0.73,1.04)$ & 0.12 \\
\hline GI perforation & 6 & 212 & 9 & 223 & 2 & $1.05(0.11,10.25)$ & 0.96 \\
\hline Hypertension & 27 & 212 & 26 & 223 & 2 & $1.10(0.70,1.73)$ & 0.68 \\
\hline Treated for hyperglycaemia & 33 & 181 & 15 & 190 & 1 & $2.31(1.30,4.11)$ & $<0.01$ \\
\hline Treated for PDA & 72 & 181 & 78 & 190 & 1 & $0.97(0.76,1.24)$ & 0.80 \\
\hline IVH grade III-IV & 2 & 181 & 3 & 190 & 1 & $0.70(0.12,4.14)$ & 0.69 \\
\hline PVL & 7 & 181 & 9 & 190 & 1 & $0.82(0.31,2.15)$ & 0.68 \\
\hline NEC & 19 & 212 & 22 & 223 & 2 & $0.91(0.51,1.63)$ & 0.75 \\
\hline ROP $>$ Grade II & 44 & 181 & 42 & 190 & 1 & $1.10(0.76,1.59)$ & 0.62 \\
\hline Duration of respiratory support & & 212 & & 223 & 2 & $1.68(-3.31,6.67)$ & 0.51 \\
\hline Death until last FU & 9 & 29 & 12 & 29 & 1 & $0.75(0.37,1.50)$ & 0.42 \\
\hline Survival without NDI (any) & 9 & 28 & 7 & 29 & 1 & $1.33(0.57,3.09)$ & 0.50 \\
\hline Cerebral palsy (survivors and FU) & 3 & 20 & 1 & 17 & 1 & $2.55[0.29,22.31]$ & 0.40 \\
\hline
\end{tabular}


There is a modest but statistically significant increase in the chance of survival without BPD after receiving early postnatal hydrocortisone with an estimated NNT of 18 infants, although the imprecision of this estimate is acknowledged in the wide confidence interval. The sub-group analysis confirmed this effect with a smaller NNT of 13. Importantly, the follow-up studies, which included a total of 898 infants from 4 studies, demonstrated a significant increase in survival without moderate-to-severe NDI, with an NNT of 14. The incidence of cerebral palsy in survivors and NDI at follow-up was comparable between the two groups of infants. Though many of the studies did not report follow-up, the favourable neurodevelopmental results would be reassuring for clinicians that the long-term effects of early postnatal hydrocortisone use are in sharp contrast to those of early dexamethasone use in preterm infants [6]. However, we have only been able to analyse neurodevelopmental outcomes up to 2 years of age. One small study, involving 51 preterm infants, with longer-term follow up, have reported increasing trends towards NDI in infants receiving hydrocortisone at 5-7 years of age [34], suggesting collection of longer-term data would be prudent. Significantly more infants who received hydrocortisone survived to discharge $(p=0.04)$, although this outcome failed to reach statistical significance in the sub-group analysis $(p=$ 0.06).

While the above outcomes are encouraging, use of early hydrocortisone resulted in a significantly higher risk of GI perforation, with an NNH of 30 infants. While hydrocortisone itself could cause intestinal perforation, an interaction between the steroid and indomethacin (or ibuprofen) has been strongly implicated as a significant contributor for this effect. Trials reporting increased incidence of GI perforation all used hydrocortisone with concurrent medical treatment for PDA [22, 26, 27, 29]. A similar interaction between early systemic dexamethasone and indomethacin were also noted in earlier studies [40]. Bourchier et al. [23] did not report an increased incidence of GI perforation, although this trial used the highest cumulative dose of early hydrocortisone but not in combination with PDA treatment. Use of ibuprofen for PDA was excluded from the PREMILOC trial in the first $24 \mathrm{~h}$ of life to avoid spontaneous GI perforations [20]. While these results generate serious concern, current clinical practice for managing PDAs are changing to a more conservative approach [41], since the spontaneous closure rate of PDAs remain high and early prophylactic treatment has failed to demonstrate significant clinical benefits. In addition, use of antenatal and postnatal steroids possibly decreases the incidence of PDA due to the inhibition of arachidonic acid and its metabolites, which have a significant effect on the patency of the duct [42].

The regime of early hydrocortisone was variable among the trials, but there were two broad groups: two trials used a total dose of $\geq 30 \mathrm{mg} / \mathrm{kg}$ but did not report any respiratory outcomes [18] or were primarily aimed for blood pressure management [23]; the rest used cumulative doses of $\leq 15 \mathrm{mg} / \mathrm{kg}$ including the five trials which used hydrocortisone for treatment of BPD. The chronic replacement dose of hydrocortisone in newborn infants, as recommended in the British National Formulary for Children (https://bnfc.nice.org.uk/ drug/hydrocortisone.html), is $8-10 \mathrm{mg} / \mathrm{m}^{2} /$ day, which is approximately equal to $1 \mathrm{mg} / \mathrm{kg} / \mathrm{day}$. The only appropriately powered trial, which had respiratory end-points as its primary outcome used this dose of hydrocortisone (cumulative dose 8 . $5 \mathrm{mg} / \mathrm{kg}$ over 10 days) and demonstrated significant clinical benefits [20]. While the most appropriate dose of hydrocortisone cannot conclusively be recommended from these results, the dose regime used by the PREMILOC trial seems to be safe and effective for survival without BPD in preterm infants. Four trials undertook formal adrenal stimulation tests after the course of hydrocortisone and reported no significant difference in cortisol levels, thus allaying fears of cortical suppression [20, 23, 27, 43].

Our review has several strengths. We have conducted a thorough electronic and manual search and believe that we have identified all published trials of hydrocortisone use in preterm infants, including two studies which are not included in the Cochrane review. Three authors have independently been involved in short listing and data collection, with joint crosschecking of all data and results. We have excluded trials where the individual effect of hydrocortisone could not be ascertained due to the use of concurrent drugs with known effects on BPD. Our analysis follows standard methods as recommended by the Cochrane collaboration (http://handbook-5-1.cochrane.org/). We have also looked at clinically relevant outcomes. Although many of the trials were not intended for the prevention of BPD but reported this outcome, we undertook a sub-group analysis by excluding these trials to reach robust conclusions. However, there are several limitations which are mostly related to the original studies. A number of trials in our analysis have included small numbers of infants increasing the chance of a type-I error [44], although they have all received lower weightage in the analyses. The increase in the incidence of gastrointestinal perforation with early systemic hydrocortisone remains of concern for clinicians, although this was associated mostly with concurrent treatment for PDA. However, this significant difference did not seem to have an overall effect in any other outcomes, including survival. In addition, early hydrocortisone seems to have a treatment-sparing effect on PDAs, which may mitigate some of this concern. While the long-term outcomes are reassuring, we acknowledge the reduction in confidence in this outcome due to incomplete follow-up in studies. The Premiloc study [20] used the Brunet-Lezine test to assess neurodevelopment at follow-up, while most of the other studies used variations of the Bailey's test for this assessment. One study from Brazil, comparing these two assessment 
methods, reported moderate correlation between them in most domains but strong correlation in the language domain [45]. However, this limits our ability to interpret the results from the long-term outcomes.

\section{Conclusions}

Early systemic hydrocortisone in preterm infants is effective in increasing the chances of survival without BPD at 36 weeks postmenstrual age. Incomplete long-term follow-up suggests significantly increased chance of survival without moderateto-severe NDI up to 2 years of age, although the methods used to assess this outcome were inconsistent. An increased risk of GI perforation, mostly in conjunction with early treatment for PDA, remains of concern. Future trials should focus on ascertaining the most appropriate dose of early hydrocortisone in preterm infants for the prevention of BPD and undertake a longer period of follow-up to conclusively establish safety. In addition, recent trials of alternative delivery methods of early steroids have also shown encouraging results and should be further studied so that the optimum strategy to reduce BPD can be identified in these vulnerable infants.

Use of systemic hydrocortisone beyond the first week of life, especially in infants who become ventilator dependent, needs further research. Currently, one ongoing trial is recruiting infants in the second week of life to receive systemic hydrocortisone (https://clinicaltrials.gov/ct2/ show/NCT01353313). Results from trials using late dexamethasone (https://www.npeu.ox.ac.uk/minidex) may also increase our knowledge in this area.

Acknowledgements We would like to sincerely thank Dr. Willian John Watkins at Cardiff University for his input into the statistical methods and analysis.

Authors' contributions IPM: Individually shortlisted studies, designed data collection form, extracted data from included studies, interpreted results, co-authored first draft, critically revised all subsequent drafts and approved final draft before submission.

NG: Individually shortlisted studies, extracted data from included studies, interpreted results, co-authored first draft, critically revised all subsequent drafts and approved final draft before submission.

MC: Conceptualised and designed overall study, prepared and ran searches, cross-checked shortlisted articles and extracted data, analysed extracted data, interpreted results, co-authored first draft, critically revised all subsequent drafts and approved final draft before submission. MC is the guarantor of the manuscript.

\section{Compliance with ethical standards}

Conflict of interest The authors declare that they have no conflict of interest.

Ethical approval This article does not contain any studies with human participants or animals performed by any of the authors.
Open Access This article is distributed under the terms of the Creative Commons Attribution 4.0 International License (http:// creativecommons.org/licenses/by/4.0/), which permits unrestricted use, distribution, and reproduction in any medium, provided you give appropriate credit to the original author(s) and the source, provide a link to the Creative Commons license, and indicate if changes were made.

\section{References}

1. Kinsella JP, Greenough A, Abman SH (2006) Bronchopulmonary dysplasia. Lancet 367(9520):1421-1431

2. Vom Hove M et al (2014) Pulmonary outcome in former preterm, very low birth weight children with bronchopulmonary dysplasia: a case-control follow-up at school age. J Pediatr 164(1):40-45 e4

3. Bolton CE, Bush A, Hurst JR, Kotecha S, McGarvey L (2015) Lung consequences in adults born prematurely. Thorax 70(6): 574-580

4. Anderson PJ, Doyle LW (2006) Neurodevelopmental outcome of bronchopulmonary dysplasia. Semin Perinatol 30(4):227-232

5. Chakraborty M, McGreal EP, Kotecha S (2010) Acute lung injury in preterm newborn infants: mechanisms and management. Paediatr Respir Rev 11(3):162-70; quiz 170

6. Doyle LW, Ehrenkranz RA, Halliday HL (2014) Early ( $<8$ days) postnatal corticosteroids for preventing chronic lung disease in preterm infants. Cochrane Database Syst Rev 5:CD001146

7. Doyle LW, Ehrenkranz RA, Halliday HL (2014) Late (> 7 days) postnatal corticosteroids for chronic lung disease in preterm infants. Cochrane Database Syst Rev 5:CD001145

8. Shinwell ES et al (2003) Neonatologists are using much less dexamethasone. Arch Dis Child Fetal Neonatal Ed 88(5):F432-F433

9. Kersbergen KJ, de Vries LS, van Kooij BJM, Išgum I, Rademaker KJ, van Bel F, Hüppi PS, Dubois J, Groenendaal F, Benders MJNL (2013) Hydrocortisone treatment for bronchopulmonary dysplasia and brain volumes in preterm infants. J Pediatr 163(3):666-71 e1

10. Rademaker KJ, de Vries LS, Uiterwaal CSPM, Groenendaal F, Grobbee DE, van Bel F (2008) Postnatal hydrocortisone treatment for chronic lung disease in the preterm newborn and long-term neurodevelopmental follow-up. Arch Dis Child Fetal Neonatal Ed 93(1):F58-F63

11. Yamasaki C, Uchiyama A, Nakanishi H, Masumoto K, Aoyagi H, Washio Y, Totsu S, Imai K, Kusuda S (2012) Hydrocortisone and long-term outcomes in very-low-birthweight infants. Pediatr Int 54(4):465-470

12. Doyle LW, Ehrenkranz RA, Halliday HL (2010) Postnatal hydrocortisone for preventing or treating bronchopulmonary dysplasia in preterm infants: a systematic review. Neonatology 98(2):111-117

13. Jobe AH, Bancalari E (2001) Bronchopulmonary dysplasia. Am J Respir Crit Care Med 163(7):1723-1729

14. Papile LA, Burstein J, Burstein R, Koffler H (1978) Incidence and evolution of subependymal and intraventricular hemorrhage: a study of infants with birth weights less than 1,500 gm. J Pediatr 92(4):529-534

15. Walsh MC, Kliegman RM (1986) Necrotizing enterocolitis: treatment based on staging criteria. Pediatr Clin N Am 33(1):179-201

16. Wan $\mathrm{X}$ et al (2014) Estimating the sample mean and standard deviation from the sample size, median, range and/or interquartile range. BMC Med Res Methodol 14:135

17. Newcombe RG (1998) Interval estimation for the difference between independent proportions: comparison of eleven methods. Stat Med 17(8):873-890 
18. Baden M et al (1972) A controlled trial of hydrocortisone therapy in infants with respiratory distress syndrome. Pediatrics 50(4):526534

19. Batton BJ et al (2012) Feasibility study of early blood pressure management in extremely preterm infants. J Pediatr 161(1):65-69 e1

20. Baud O, Maury L, Lebail F, Ramful D, el Moussawi F, Nicaise C, Zupan-Simunek V, Coursol A, Beuchée A, Bolot P, Andrini P, Mohamed D, Alberti C (2016) Effect of early low-dose hydrocortisone on survival without bronchopulmonary dysplasia in extremely preterm infants (PREMILOC): a double-blind, placebo-controlled, multicentre, randomised trial. Lancet 387(10030):1827-1836

21. Biswas S et al (2003) Pulmonary effects of triiodothyronine (T3) and hydrocortisone (HC) supplementation in preterm infants less than 30 weeks gestation: results of the THORN trial-thyroid hormone replacement in neonates. Pediatr Res 53(1):48-56

22. Bonsante F, Latorre G, Iacobelli S, Forziati V, Laforgia N, Esposito L, Mautone A (2007) Early low-dose hydrocortisone in very preterm infants: a randomized, placebo-controlled trial. Neonatology 91(4):217-221

23. Bourchier D, Weston PJ (1997) Randomised trial of dopamine compared with hydrocortisone for the treatment of hypotensive very low birthweight infants. Arch Dis Child Fetal Neonatal Ed 76(3):F174-F178

24. Efird MM, Heerens AT, Gordon PV, Bose CL, Young DA (2005) A randomized-controlled trial of prophylactic hydrocortisone supplementation for the prevention of hypotension in extremely low birth weight infants. J Perinatol 25(2):119-124

25. Hochwald O, Palegra G, Osiovich H (2014) Adding hydrocortisone as 1 st line of inotropic treatment for hypotension in very low birth weight infants. Indian J Pediatr 81(8):808-810

26. Ng PC, Lee CH, Bnur FL, Chan IH, Lee AW, Wong E, Chan HB, Lam CW, Lee BS, Fok TF (2006) A double-blind, randomized, controlled study of a "stress dose" of hydrocortisone for rescue treatment of refractory hypotension in preterm infants. Pediatrics 117(2):367-375

27. Peltoniemi O, Kari MA, Heinonen K, Saarela T, Nikolajev K, Andersson S, Voutilainen R, Hallman M (2005) Pretreatment cortisol values may predict responses to hydrocortisone administration for the prevention of bronchopulmonary dysplasia in high-risk infants. J Pediatr 146(5):632-637

28. Watterberg KL, Gerdes JS, Gifford KL, Lin HM (1999) Prophylaxis against early adrenal insufficiency to prevent chronic lung disease in premature infants. Pediatrics 104(6):1258-1263

29. Watterberg KL, Gerdes JS, Cole CH, Aucott SW, Thilo EH, Mammel MC, Couser RJ, Garland JS, Rozycki HJ, Leach CL, Backstrom C, Shaffer ML (2004) Prophylaxis of early adrenal insufficiency to prevent bronchopulmonary dysplasia: a multicenter trial. Pediatrics 114(6):1649-1657

30. Dobryanskyy D et al (2012) Clinical effectiveness of early administration of caffeine and low-dose hydrocortisone to preterm newborns with a high risk of BPD development. In: 4th Congress of the European Academy of Paediatric Societies. Archives of disease in childhood. Turkey, Istanbul, p A119

31. Baud O, Trousson C, Biran V, Leroy E, Mohamed D, Alberti C, for the PREMILOC Trial Group (2017) Association between early low-dose hydrocortisone therapy in extremely preterm neonates and neurodevelopmental outcomes at 2 years of age. JAMA 317(13):1329-1337

32. Fitzhardinge PM et al (1974) Sequelae of early steroid administration to the newborn infant. Pediatrics 53(6):877-883

33. Peltoniemi OM, Lano A, Puosi R, Yliherva A, Bonsante F, Kari MA, Hallman M, Neonatal Hydrocortisone Working Group (2009)
Trial of early neonatal hydrocortisone: two-year follow-up. Neonatology 95(3):240-247

34. Peltoniemi OM, Lano A, Yliherva A, Kari MA, Hallman M, for The Neonatal Hydrocortisone Working Group (2016) Randomised trial of early neonatal hydrocortisone demonstrates potential undesired effects on neurodevelopment at preschool age. Acta Paediatr 105(2):159-164

35. Watterberg KL, Shaffer ML, Mishefske MJ, Leach CL, Mammel MC, Couser RJ, Abbasi S, Cole CH, Aucott SW, Thilo EH, Rozycki HJ, Lacy CB (2007) Growth and neurodevelopmental outcomes after early low-dose hydrocortisone treatment in extremely low birth weight infants. Pediatrics 120(1):40-48

36. Kazzi NJ, Brans YW, Poland RL (1990) Dexamethasone effects on the hospital course of infants with bronchopulmonary dysplasia who are dependent on artificial ventilation. Pediatrics 86(5):722727

37. Parikh NA, Kennedy KA, Lasky RE, McDavid GE, Tyson JE (2013) Pilot randomized trial of hydrocortisone in ventilatordependent extremely preterm infants: effects on regional brain volumes. J Pediatr 162(4):685-690.e1

38. Onland W, Cools F, Kroon A, Rademaker K, Merkus MP, Dijk PH, van Straaten HL, te Pas AB, Mohns T, Bruneel E, van Heijst AF, Kramer BW, Debeer A, Zonnenberg I, Marechal Y, Blom H, Plaskie K, Offringa M, van Kaam AH, for the STOP-BPD Study Group (2019) Effect of hydrocortisone therapy initiated 7 to 14 days after birth on mortality or bronchopulmonary dysplasia among very preterm infants receiving mechanical ventilation: a randomized clinical trial. JAMA 321(4):354-363

39. Parikh NA, Kennedy KA, Lasky RE, Tyson JE (2015) Neurodevelopmental outcomes of extremely preterm infants randomized to stress dose hydrocortisone. PLoS One 10(9):e0137051

40. Stark AR, Carlo WA, Tyson JE, Papile LA, Wright LL, Shankaran S, Donovan EF, Oh W, Bauer CR, Saha S, Poole WK, Stoll BJ, Fanaroff AA, Ehrenkranz RA, Korones SB, Stevenson DK (2001) Adverse effects of early dexamethasone treatment in extremelylow-birth-weight infants. National Institute of Child Health and Human Development neonatal research network. N Engl J Med 344(2):95-101

41. Ngo S, Profit J, Gould JB, Lee HC (2017) Trends in patent ductus arteriosus diagnosis and management for very low birth weight infants. Pediatrics 139(4):e20162390

42. Gupta $\mathrm{S}$ et al (2012) Postnatal corticosteroids for prevention and treatment of chronic lung disease in the preterm newborn. Int $\mathrm{J}$ Pediatr 2012:315642

43. Watterberg KL, Shaffer ML, Garland JS, Thilo EH, Mammel MC, Couser RJ, Aucott SW, Leach CL, Cole CH, Gerdes JS, Rozycki HJ, Backstrom C (2005) Effect of dose on response to adrenocorticotropin in extremely low birth weight infants. J Clin Endocrinol Metab 90(12):6380-6385

44. Stone DL, Rosopa PJ (2017) The advantages and limitations of using meta-analysis in human resource management research. Hum Resour Manag Rev 27(1):1-7

45. Cardoso FGC, Formiga CKMR, Bizinotto T, Tessler RB, Rosa Neto F (2017) Concurrent validity of the BRUNET-LÉZINE scale with the BAYLEY scale for assessment of the development of preterm infants up to two years. Revista Paulista de Pediatria 35(2):144-150

Publisher's note Springer Nature remains neutral with regard to jurisdictional claims in published maps and institutional affiliations. 